to an encysted stone, which was removed subsequently. In looking over the cases of multiple stone, I was surprised to find how few present facets, and I believe it may almost be laid down as an axiom that facets only occur when one or more of the stones is to some extent fixed. The moral to be drawn is : Always search the bladder thoroughly as a matter of rontine.

Group D. - Stones of bladcler formation due to chronic cystitis (Nos. 1, 2, 11, 13,16, 19, 20, 26, 35, 41 A. and B., 42 A. and 1., 45 . and s.; 16 out of 50 cases). The intervals varied from 7 to 47 months; average 191 months. This group may fairly be divided into two subgroups. In subgroup $a$, the cystitis was present before the operation ( $\mathrm{Nos} 1,2,11,13,19,26,41$ i., 42 is., $45 \mathrm{~B}$ ) In these cases the operation of cystotomy, with drainage, might fairly have been expected to cure the cystitis, by removing the irritat. ing stone and allowing cscape of the decomposing mucus. In Sub. group $b$, the cystitis was directly caused by the operation (Nos. 16, $20,35,39,41 \Lambda, 42 \mathrm{~A}, 45 \Lambda$.). In this group, the calculi are composed of soft phosphates with mucus, and would be more correctly termed agglomerations than concretions. These cases are frequently complicated by fistula, periueal or rectal ; and these two conditions mutually interact; the cystitis predisposing to fistula, and the fistula prolonging the cystitis.

These views are in the main those held by the late J. G. Crosse, and it does credit to his surgical acuteness that, from the meagre smount of twolve cases, he should have drawn such accurate conclusions. I cannot conclude this better than by quoting his words (page 164). "So far as recurrence of the disease is connected with the first operation, a large stone leaves little subsequent danger; the most likely cases for a relapse being those where the stone is small, and breaks in the extraction, the wound healing quickly afterwards, so as to prevent the escape of fragments. Next to fragments loft in the bladder, an imperfect cure after the first operation from rectal or perinæal fistula remaining may be regarded as almost certain to cause a relapse. Without such circumstances being prescnt, a second stone may form unavoidably from small calculi, previously occupying the cavities of the kidneys, descending into the bladder and remaining there, or from continuance or fresh occurrence of any deranged condition of the urinary organs capable of giving rise to a calcareous deposit. When a second concretion forms, the symptoms rarely become so severe as to induce submission to a second operation within twelve months ; and where several years of health elapse, the return of the disease is independent of the first operation, and of any morbid condition of the bladder then present."

\section{A CASE OF EXTRA-UTERINE PREGNANCY :}

DEATH OF THE FETUS AT FOUR MONTHS : INTESTINAL OBSTRUOTION FROM PRESSURE: REMOVAL OF THE FETUS BY PEPINEAL SECTION : RECOVERY.

BY GEOLGE J. ROBERTSON, M.B., Surgeon to the Oldham Inflrmary.

I was called to see Lavinia B., on May 29th, 1885, when she was in a state of well-marked bat not profound collapse, very sick, and sweating profusely. She was 33 yeurs of age, and the mother of two children, aged four and two years. Previously regular, she missed her period ton weeks ago, and from her symptoms believed herself to be pregnant.

On May 22nd, she was suddenly seized with severe pain in the lower part of the abdomen, followed by faintness and sickness. The present attack was ushered in by pain in the same region, but far more agonising. With the greatest difficulty, she was able to cross the room to summon assistance. At this time, the abdomen was quite flaccid, and free from tenderness; the uterus was somewhat onlarged; in the bef forma was a tumour, the characters of which will be presently insow In the course of a few days, the condition of col. lapse panat. of ; while the abdomen became slightly distended and tender ospecially in the hypogastric region, where she suffered fivit shmpiatabbing pains.

During Jote bndivily, the patient suffered frequently from colicky pains in therwing; when were always induced when she sat up in bed for any bitglit of time or attempted to walk. She had two attacks similat to thome described, but less severe, and followed, like it, by slight aldoingul distension and tenderness. There was no negular menstruationa June 24th, and again on the 30 th, she had a slight discharge of wed; went neither then nor at any time was a membrane or solid suitutines'ef any kind expelled.

The tumour, wher: fint iverved, was about the size and shape of an orange, situated to the left of the utcrus, and quito separate from it ; it was also painful on pressure, but the tenderness passed off in the course of a few days, to be present again after the other attacks mentioned above. It was neither so smooth nor so hard as a fibroid, yielding to the pressure of the finger, but giving no sensation of fluidity. It seemed to be firmly fixed in the pelvis. It slowly but steadily increased in size till it bulged above the brim. Stethoscopic examination gave no result. The uterus remained unaltered in size, but was displaced upwards and forwards, so that the fundus could be felt on placing the hand on the hypogastrium.

Toward the end of July, I thought the tumour was becoming smaller, an opinion which further observation confirmed.

On August 12th, she complaincl of pain in the epigastrium, suffered from sickness, and vomited slightly ; she also had intermittent attacks of pain in the bowels; the abdomen was becoming distended.

August 13th. She had sickness, hiccough, and vomiting; the romited matters were bilious and in small quantity. The abdomen was more distended, and pains were more severe, though still intermittent. There was no action of the bowels.

August 14th. She had incessant vomiting of stcreuraceous matter during the night. There was dulness on percussion over the ascending colon : the transverse and descending colon were tense and tympanitic; the outline of three coils of distended small intestine was observed on the left of the umbilicus. The patient exhibited the usual symptoms of intestinal obstruction. Though greatly exhausted, and with a pulse scarcely perceptible, she was quite conscions, and remarked that the pains were like "labour pains." The tumour was quite immovable, and bulged more prominently in the pelvis than before the present attack. Encmata were ineffective.

Diagnosis and Treatmcnt. - When the case was first seen, the previous history, the tumour, and the characters of the attack gave rise to strong suspicion of tubal pregnancy that had undergone rupture. During the following two months the development of the external signs of pregnancy, and the continued absence of menstruation with. out increase in the size of the utcrus, together with the colicky pains in the bowels, and the steady rate of increase of the tumour, gave additional strength to this view; nor, on the supposition of the death of the fœetus, was it weakened by the gradunl diminution of the tumour. It must be confessed, however, that the occurrence of this symptom shook my confidence in the opinion I had formed, without suggesting a probable alternative.

There could be little doubt that the intestinal obstruction arose from the pressure of the tumour upon the large bowel. Whatever was the structure of the tumour, it was, and had been ever since it was first examined, pressing upon the pelvic floor, to which there were good reasons for believing it was adherent. Immediate interference was required to relieve the obstruction. In preference to colotomy, treatment was directed to attain the double object of relieving the obstruction, and of dealing with the tumour.

The operation to be described seemed to offer a reasonable chance of success if it were an extra-uterine pregnancy, an abscess, or a hæmatocele; and, if none of these, it would not prevent recourse to other methols of treatment, and might assist in the diagnosis.

Opcration.-On August 14th, at 6 P.M., the patient was chloroformed, and placed in the lithotomy position. A straight incision from before backwards, two inches in length, was made through the skin and fascia of the perinxum, commencing a little in front of the anus, and being about an inch and a half to the left of the middle line. The left index-finger was now pressed along the left vaginal wall, with the tip resting upon the tumour in order to serve as a guide; and by digital dissection, aided by the knife, to divide a few fibres of the levator ani, the most prominent part of the tumour was reached. Into it I passed a bladder-trocar, which, after it penetrated the sac, was pushed onward without encountering any solid resistance. On withdrawing the trocar, there escaped from the cannula a few drops of dark brown fluid, which had neither the colour nor the consistence of freshly shed blood. I then enlarged the opening in the sac, withdrew the cannula, and introduced my finger. It passed tlirough a very friable substance, a small portion of which was removed for inspection. It looked likc partially decolorised blood-clot. Not quite satisfied, I brought down a second portion, the structure of which was distinctly placental. The foetus was next discovered; a foot being drawn into the wound was seized with a long polypus-forceps, and the wholo removed by gentle traction. The umbilical cord was divided, and replaced in the cavity after removal of a small quantity of old blood. clot; so far, there had been no hæmorrhage. For the purpose of draining and irrigating by the method described in the Melical Chronicle, October, November, and December, 1884, two rubber tubes, without side holes, were tied together; the one for drainage having a 
half inch diameter, the other for irrigation being of small size, and about two foet in length; these were inserted into the cavity. Scarcely had this been done, and it was done carefully and without difficulty, when alarming hxmorrhago set in. As speedily as possible I irrigated with very hot water, with the result that bleeding stopped before serious loss had been sustained; thereafter pieces of absorbent cotton soaked in sublimate solution were packed round the tubes in the wound, and outside it. This dressing was retained in position by a T-bandage, to which, also, the tubes were secured. I omit details of the method of drainage, except such as are necessary to make the progress of the ease intelligible. It may be stated that the discharges were carried off entirely through the drainago-tubc, from which they passed in to a receptacle ; that the dressing required to be removed only when it became soiled with urine or freces; and that, by means of a Higginson's syriuge attached to the smaller tube, irrigation was effected without disturbing the patient's posture, sometimes even without her knowledge. The fluid used was simple warm water, unless when it is stated otherwise.

August 15th. At midnight she vomited a large quantity of offensive fluid, after which she passed a comfortable night. Temperature, at 10 A.M., $98.4^{\circ}$. There was a discharge of 5 to 6 ounces of blood. All symptoms of obstruction had disappeared ; the bowels were beginning to act ; an enema was orderel, with the result that they continued to be moved during the rest of the day.

August 16th, 10 A.M. Temperature 98.6 $6^{\circ}$. During twenty-four hours, four or five ounces of blood free from odour had been discharged. The bowels had been moved several times during the night. The nurse had failed to pass the catheter. The dressing and bedclothes were soaked with urine.-9 P.M. Pulse 120, intermittent and shaky. Temperature 99.8 . She had sharp pains in the bowels, though flatus and urine passed freely. Opium was ordered.

August 17 th. Pulse 125 ; temperature $100.4^{\circ}$. She was very restless during the greater part of the night. There was no discharge from the drainage-tube till early Inorning, when over two ounces escaped, after which she felt much relieved. On examination, I found that the tubes, though still in the wound, were withdrawn from the cavity, the explanation being that the nurse had, the previous afternoon, loosened the bandage, because the patient complained of being uncomfortable. On removing the tubes and introducing my finger into the cavity, a considerable quantity of very offensive bloody discharge escaped. The tubes were replaced, and the cavity thoronghly washed out. Irrigation was ordered to be done every two hours. In the evening, the patient was much better. Temporature $98.6^{\circ}$; pulse 108 , steadier and stronger.

August 19th. T'emperature $98.8^{\circ}$. The patient was resting well, and taking nourishment freely. The discharge was still bloody, and now contained a quantity of débris. As the fluid did not flow freely in irrigating, the tubes were withdrawn, and along with them came the umbilical cord and numerous shreds of placenta. Irrigation was ordered to be done every two hours.

August 22nd. The discharge was now free from blood. The tube, being again blocked, was taken out. Introducing my finger into the cavity, I found that the placenta was still adherent, and proceeded cautiously to detach it, which I succeeded in doing without exciting any hrmorrhage. Then, by pressure of the finger, I broke it up, and removed it piecemeal by the aid of a long polypus-forceps. The tubes being reapplied, thorough irrigation with carbolic lotion ( 1 in 40) completed the process, which occupied nearly an hour. The patient, who had not been chloroformed, boing very faint and exhausted, was ordered brandy and opium.

August 23rd. The temperature was normal ; there was no bad symptom of any kind. From this date, the improvement in her general condition was rapid and uninterrupted. The debris that came away in irrigating consisted now unly of small particles without any pus.

September 1st. There had been no hitch of any kind since the last date. There was now no debris, nor fotor, and merely a trace of pus. The patient was allowed to sit up in bed.

September 6th. I found her downstairs, attending to her household duties. The discharge now contained nothing but a little mucus. I withdrew the tubes from the sac, leaving them in the wound for some days, when, as no bad symptom arose, they were finally removed, after which the perineal wound speedily healci.

October 28th. The patient menstruated a fortnight ago in her usual way. There was some rigidity in the left fornix, and a cordlike hardness could be felt along the left vaginal wall in the track of the wound. The uterus occupied its normal position, was movable, and in other respects free from disorder.

Nores. - The following observations upon the tumour and its con. tents during and after the operation may be of interest. The sac, or at least that portion of it which was incised, was contractile. I was conscious of my finger being grasped when introduced into the open. ing made in it, the closure of which, on removal of the finger, was so coinplete, as to cause some difficulty in finding it again. It was also dilatable, as, in extracting the foitus, the wound was not enlarged by rupture. The position of the wound was about the centre of the floor, and afforded the greatest facility for exploration. Internal to it was the placenta, adherent to the floor and inner wall, while the fotus lay in the outer portion. The cavity was oval in shape, with its greatest diameter in the transverse diameter of the pelvis. In cxtracting the fuetus, and on two or three occasions during the operation, there were observed well-marked labour-paius. The footus appeared to be about four months, shrunken and macerated to a moderate degree. Tho placenta was considerably larger than is usual in a four months' pregnancy. The small portion removed for inspection was in the same condition as the futus, and so, no doubt, was the entire fuetal division of it. As the outer border lay close to, if it were not involved in, the incision in the sac, the detachment of a small portion in introducing the tubes explains the harmorrbage that occurred. The wound being about the centre of the floor of the cyst, as has been mentioned, when the finger was inserted at the time of operation, there was an equal division of the cavity internally and externally to it. On September 6th, when the tubes were removed, I took the opportunity of making an examination, whon $I$ found that the external division was entirely obliterated; tho finger lay in contact with the outer wall.

REMARKs. - It appears probable that the attack of obstruction of the bowels was preceded and induced by false labour, the pains of which jammed down the tumour in the pelvis, causing pressure upon the bowel. Perineal section is easy of performance; considered ana. tomically, it is a safe procedure, no important vascular or other structure beiug, with ordinary care, endangered; it affords a direct and dependent routo to the pelvic floor, and is, therefore, woll adapted for the drainage of fluids in that situation. These advan tages might, to a considerable extent, be claimed for vaginal section, which, however, establishes a fistulous communication between the vagina and the tumour, and is in this respect so objectionable as to be seldom practised. In a large number of cases that are amenable to treatment by incision and drainage, as opposed to excision, the tumour is intimately adherent to the pelvic floor, as, for instance, in abscess, pyosalpinx, and hamatocele. It is this condition that makes excision difficult and dangerous, sometimes impossible ; and it is pre cisely the condition that is required for perineal section. Comparing the latter operation with abdoninal section for the purpose of drainage, it would seem to be safer, inasmuch as it does not nocessitate opening into the peritoneal cavity, and is free from the risk attendant upon stitching the sac to the abdominal wall; and it appears to afford a better outlet for discharge.

ON DRAINAGE OF THE BLADDER.

WITH SPECIAL AJPGRENCE TO A POSTPROSTATIC OPERATION. BY E. H. HOWLET'I, F.R.C.S.

Surarows have long been acquainted with different methods of emptying the bladder other than through the urethra. Endeavours have, however, been shiefly directed to the alleviation of immediate troubles, the tiding over till such time as nature shall reassert herself, and remove the temporary obstruction to the flow of urine. Of these methods, the one most in favour is suprapubic aspiration of the bladder, a proceeding generally considered to be both safe and expeditious. Individually, I have the highest opinion of the proceeding, and in any difficult case of retention of urine would rather aspirate the bladder than interfere in any except the most gentle manner with the urethral track; and I venture to think that, were suprapubic aspiration more frequently employed, we should see and hear less of alarming symptoms following the use of the catheter; indeed, it requires but a limited experience to come across cases hurried to an early grave by the too liberal employment of that instrument. As illustrating $m y$ confidence in aspiration, I here incidentally mention the case of a man who called at $m y$ house in December last, in the agonies of acute retention of urine. There was a history of stricture of some years' standing, with a diminished stream on micturition. The obvious cause for the retention was wanting, as the man, at the time of seizure, was following his usual occupation as a clerk. Haring failed to introduce either a soft or a metal catheter through the stricture, and preferring not to meddle much with the urethra in its ex. cited condition, I proceeded to suprapubic puncture, using a small 